\title{
Vitamin/Mineral Supplements for Children and Adults with Autism
}

\section{James B Adams*}

Director, Autism/Asperger's Research Program, President's Professor, Arizona State University, PO Box: 876106, Temple, AZ, USA

\begin{abstract}
Vitamins and minerals are the most widely used medical treatment for autism. Many research studies have demonstrated that children and adults with autism often have nutritional and metabolic problems, including problems with methylation, glutathione, oxidative stress, sulfation, lithium, and more. This review summarizes the results of several vitamin/mineral treatment studies conducted by our group, which demonstrate that vitamin/mineral supplements are highly effective in improving many nutritional and metabolic problems, and result in significant improvements in symptoms based on a large, randomized, double-blind, placebo-controlled study. We recommend that all children and adults with autism consider a 2-3 month trial of a vitamin/mineral supplement designed for individuals with autism that is similar to the one used in our studies. By starting at a low dose, and gradually increasing it, there is minimal risk of adverse effects, and many children and adults are likely to benefit, sometimes substantially.
\end{abstract}

\section{Introduction}

Autism is a developmental disability that involves major problems in communication, social understanding/interaction, and sterotyped behaviors/restricted interests. It is usually a lifelong disorder, and very difficult to treat. Vitamin/mineral supplements are one of the most widely used treatments for autism.

The definition of a "vitamin" or "essential mineral" is that the lack of that vitamin or mineral results in disease or even death. The Recommended Daily Allowance (RDA) is the minimum amount required to prevent disease, but may be less than the amount needed for optimal mental and physical health. Most people in the US consume less than the RDA of one or more vitamins and minerals. For example, many women lack enough calcium and iron, leading to osteoporosis and anemia, respectively.

Vitamins and minerals are available in vegetables, fruits, meat, and other sources. However, the typical U.S. diet is lacking in key vitamins and minerals, so many people need to take a supplement. Children with autism seem to have an increased need for certain vitamins and minerals.

The primary role of vitamins and minerals is to act as enzymatic co-factors for many important reactions in the body. For example, the production of serotonin (an important neurotransmitter) requires the conversion of 5-HTP to serotonin, and vitamin B6 is the co-factor for the enzyme for that reaction, meaning that it greatly accelerates the rate of the reaction. If you have too little vitamin $\mathrm{B} 6$, then the reaction is slow, and less serotonin is produced. Vitamin B6 is involved in over 100 enzymatic reactions in the body, including the production of several neurotransmitters. Some vitamins and minerals are involved in hundreds of enzymatic reactions, affecting most of the major metabolic pathways in the body. To put it simply, vitamins and minerals are essential for a healthy life.

\section{Research on Individual Vitamin/Mineral Supplements for Children and Adults with Autism}

Surveys of 539 physicians found that vitamin/mineral supplements are among the most widely recommended medical interventions for autism, and are recommended by $49 \%$ of physicians for children with autism [1]. However, there have been relatively few treatment studies of vitamin/mineral supplements for children with autism.

Vitamins and minerals are important anti-oxidants, and there are over 26 studies reporting on biomarkers of increased oxidative stress in children with autism Frustaci et al. [2] suggesting that children with autism may have decreased levels of vitamins/minerals and/or increased need for them. Three studies demonstrated that children with autism have increased oxidative stress, impaired methylation (decreased SAM), and decreased glutathione, [3-5] compared to neurotypical children. Two open-label studies found that nutritional supplementation - with vitamin methyl-B12, folinic acid (a special type of folic acid), and (in one of the studies) trimethylglycine resulted in significant improvements in oxidative stress, methylation, and glutathione [3,4]. A 30-week, double-blind, placebo-controlled study [6] with high-dose vitamin C (110 mg / kg), an important antioxidant, found a reduction in autism severity as measured by the RitvoFreeman scale. One small open-label study [7] with NADH (the active form of vitamin B3) found that two weeks of treatment was effective at improving methylation, glutathione, $\mathrm{NADH}$, and ribose. Very high dose vitamin B6 with magnesium has been studied in eleven doubleblind, placebo-controlled studies, with almost all showing positive behavioral improvements. The studies were somewhat limited by methodological problems including small sample size and the use of assessment tools of limited validity, but overall the studies strongly suggest that it is beneficial for about $30 \%$ of children and adults with autism [8].

Overall, these studies demonstrate that most children with autism have problems with increased oxidative stress, methylation, and glutathione, and that certain vitamins and minerals can be helpful to them.

\section{Research on Multi-Vitamin/Mineral Supplements for Children and Adults with Autism}

\section{4 study}

In 2004 we published a small pilot study of a multi-vitamin/mineral supplement for children with ASD [9], which used a randomized, double-blind, placebo-controlled design. None of the children in the

${ }^{*}$ Corresponding author: James B Adams, Ph.D, Director, Autism/Asperger's Research Program, President's Professor, Arizona State University, PO Box: 876106, Temple, AZ, USA, Tel: 480-965-3316; E-mail: jim.adams@asu.edu

Received February 11, 2015; Accepted February 18, 2015; Published February 28, 2015

Citation: Adams JB (2015) Vitamin/Mineral Supplements for Children and Adults with Autism. Vitam Miner 3: 127. doi:10.4172/2376-1318.1000127

Copyright: ( 2015 Adams JB. This is an open-access article distributed under the terms of the Creative Commons Attribution License, which permits unrestricted use, distribution, and reproduction in any medium, provided the original author and source are credited. 
study were on a vitamin/mineral supplement for two months prior to the study. They found that the treatment group generally improved more than the placebo group, with statistically significant greater improvements in sleep $(\mathrm{p}=0.03)$ and gastrointestinal problems $(\mathrm{p}=$ 0.03 ), both of which are very common in autism.

\section{7 / 2008 study}

Due to the promising results of the 2004 study, in 2007 / 2008 we conducted a small open-label pilot study of a customized vitamin/ mineral supplement with 10 children with ASD, which included extensive pre and post measurements of nutritional status (vitamins, minerals, amino acids) and metabolic functioning (oxidative stress, methylation, glutathione, sulfation, and neurotransmitters). The supplement was well-absorbed (as indicated by increases in blood levels and urinary excretion), and improved levels of glutathione and some neurotransmitters. The results of that pilot study were used to reformulate the supplement, adjusting the level of some ingredients slightly up or down based on the laboratory findings.

\section{8 / 2009 study}

In 2008 / 2009 this revised "second generation" supplement was used to conduct a randomized, double-blind, placebo-controlled three-month treatment study $[10,11]$. The study started with a detailed comparison study of the nutritional and metabolic status of the children with autism ( $\mathrm{N}=55$, recruited for the treatment study) vs. neurotypical children of similar age, gender and locale. The autism group had many statistically significant differences $(p<0.001)$ in their average levels of biomarkers compared to the neurotypical group, including: Low levels of biotin, glutathione, S-adenosylmethionine (SAM), uridine, plasma adenosine-5'-triphosphate (ATP), reduced nicotinamide adenine dinucleotide (NADH), reduced nicotinamide adenine dinucleotide phosphate (NADPH), plasma sulfate (free and total), and plasma tryptophan; also high levels of oxidative stress markers and plasma glutamate. A statistical analysis demonstrated significant associations between all three autism severity scales and several groups of biomarkers, including primarily vitamins, minerals, and amino acids.

The treatment part of the study involved a randomized, doubleblind, placebo-controlled three month vitamin/mineral treatment study. The study involved 141 children and adults with autism. Biomarkers of nutritional and metabolic status were measured in a subset of the participants (53 children ages 5-16). The vitamin/mineral supplement was generally well-tolerated, and individually titrated to optimum benefit. Levels of many vitamins, minerals, and biomarkers improved/increased showing good compliance and absorption. There were many statistically significant improvements in nutritional and metabolic status, including improvements in oxidative stress, methylation, glutathione, sulfate, ATP, and NADH. Most of these metabolic biomarkers improved to normal or near-normal levels. Table 1 shows results for biomarkers for oxidative stress (nitrotyrosine), methylation (uridine), and glutathione.

The supplement group had significantly greater improvements than the placebo group on the Parental Global Impressions-Revised (PGI-R, Average Change, $\mathrm{p}=0.008$ ), and on the subscores for Hyperactivity ( $\mathrm{p}$ $=0.003)$, Tantrumming $(\mathrm{p}=0.009)$, Overall $(\mathrm{p}=0.02)$, and Receptive Language $(p=0.03)$. Overall, it seemed that about $1 / 3$ of the group had no improvement, $1 / 3$ had some improvement, and $1 / 3$ had substantial improvement. The improvements were greatest in the group under age 18 , but there were some reported benefits in the adult group as well (Figure 1).

\section{1-2013 study}

From 2011 to 2013 we conducted a 12- month, randomized, singleblind, controlled study of treating children and adults with autism with a combination of 6 nutritional treatments, including an improved version of the vitamin/mineral supplement used in our 2008/2009 study. The vitamin/mineral supplement was rated by participants as one of the two most effective treatments, and the results of that study are now being written up for publication.

\section{4: Release of ANRC Essentials}

In June 2014 we decided to release an improved version of the supplement used in our 2007 / 2008, 2008 / 2009, and 2011 / 2013 studies. To prevent any financial conflict of interest, we formed a non-profit, the Autism Nutrition Research Center (ANRC), which distributes the vitamin/mineral supplement, now known as ANRC Essentials. ANRC Essentials is a comprehensive multi-vitamin/mineral supplement containing over 30 ingredients, at doses determined to be optimal based on our research studies (Table 2). Special features include:

- Relatively high (above RDA) doses of vitamins B1, B2, B3, $\mathrm{B} 5, \mathrm{~B} 6, \mathrm{~B} 12$, biotin, folate, $\mathrm{C}, \mathrm{D}$, and $\mathrm{K}$, which we believe are important for individuals with autism.

- Folate as methlytetrahydrofolate instead of folic acid (folic acid is not helpful to children with autism) [3]

\begin{tabular}{|c|c|c|c|c|c|c|}
\hline & \multirow[b]{2}{*}{ units } & \multirow[t]{2}{*}{$\begin{array}{l}\text { Neuro-typicals } \\
\quad(n=44)\end{array}$} & \multicolumn{4}{|c|}{$\begin{array}{l}\text { Arizona Treatment Group } \\
\qquad(n=18)\end{array}$} \\
\hline & & & Pre & Post & $\%$ change & $P$-value \\
\hline Plasma nitro-tyrosine & Ug / I & $\begin{aligned} & 7.4 \\
&+/-5.1 \\
&\end{aligned}$ & $\begin{aligned} & 14.1 \\
&+/-6.5 \\
&\end{aligned}$ & $\begin{aligned} & 9.9 \\
&+ /-5.4 \\
&\end{aligned}$ & $-29 \%$ & 0.004 \\
\hline Reduced plasma glutathione (GSH) & $\mathrm{nmol} / \mathrm{ml}$ & $\begin{aligned} & 4.09 \\
&+/-0.79 \\
&\end{aligned}$ & $\begin{aligned} & 3.27 \\
&+ /-0.59 \\
&\end{aligned}$ & $\begin{aligned} & 3.84 \\
&+ /-0.61 \\
&\end{aligned}$ & $+17 \%$ & 0.0008 \\
\hline Oxidized glutathione (GSSG) & $\mathrm{nmol} / \mathrm{ml}$ & $\begin{array}{l}0.362 \\
+/-0.10\end{array}$ & $\begin{array}{l}0.467 \\
+/-0.12\end{array}$ & $\begin{array}{l}0.403 \\
+/-0.09\end{array}$ & $-14 \%$ & 0.02 \\
\hline $\begin{array}{l}\text { Ratio of oxidized to reduced plasma } \\
\text { glutathione }\end{array}$ & & $\begin{array}{l}0.093 \\
+/-0.04 \\
\end{array}$ & $\begin{array}{l}0.150 \\
+/-0.05\end{array}$ & $\begin{array}{l}0.109 \\
+/-0.03\end{array}$ & $-27 \%$ & 0.002 \\
\hline $\begin{array}{c}\text { SAM } \\
(\mathrm{RBC})\end{array}$ & umol / dl & $\begin{array}{l}228.4 \\
+/-12\end{array}$ & $\begin{array}{l}218 \\
+/-17 \\
\end{array}$ & $\begin{aligned} & 230 \\
+/ / & -16\end{aligned}$ & $+6 \%$ & 0.003 \\
\hline $\begin{array}{l}\text { Uridine } \\
\text { (plasma) }\end{array}$ & $10-6 \mathrm{M}$ & $\begin{aligned} & 7.9 \\
+ & /-2.7\end{aligned}$ & $\begin{aligned} & 16.2 \\
+ & /-9.5\end{aligned}$ & $\begin{aligned} & 10.4 \\
&+/-4.7\end{aligned}$ & $-36 \%$ & 0.008 \\
\hline
\end{tabular}

Table 1: Oxidative Stress, Methylation, and Glutathione: The average levels measured in the Neurotypical group and the Autism Treatment group (pre and post) who completed the study are reported below, along with their standard deviations. The p-value for a t-test comparison of the change in the level is reported. Oxidative stress is assessed by nitrotyrosine and GSH: GSSG ratio, methylation is assessed by SAM and uridine, and glutathione is assessed by GSH [10,11]. 


\section{Parental Global Impressions - Revised}

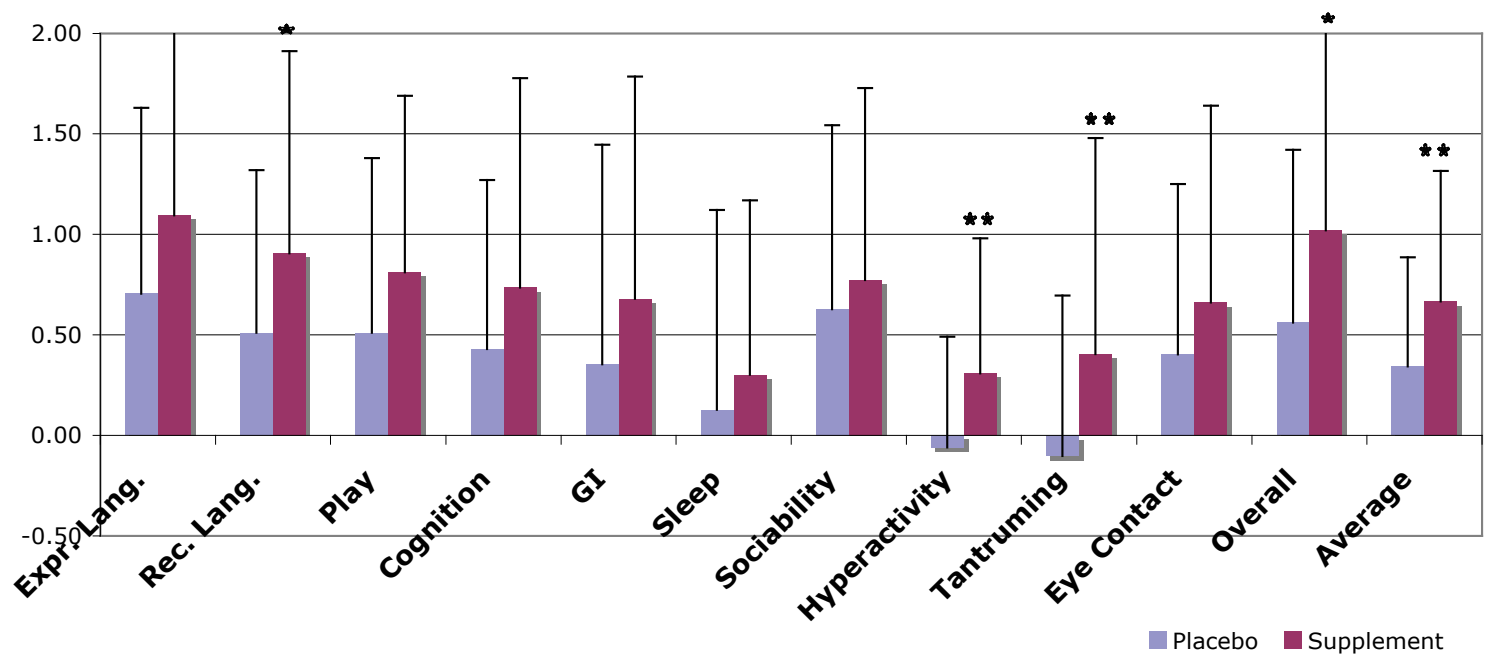

Figure 1: Results for the Parent Global Impressions - Revised. The supplement group had greater improvements in the PGI-R Average score ( $p=0.008$ ), and in the subscores for Receptive Language $(p=0.03)$, Hyperactivity $(p=0.003)$, Tantrumming $(p=0.009)$, and Overall $(p=0.02)$. The $y$-axis is from -3 (much worse) to 0 (no change) to +1 (slightly better) to +2 (better) to +3 (much better) $[10,11]$.

\begin{tabular}{|l|}
\hline ANRC Essentials Formulation (recommended dosage for a 60 pound child) \\
\hline $8000 \mathrm{IU}$ Vitamin A (as mixed carotenoids from algae) \\
\hline $500 \mathrm{mg}$ Vitamin C (as calcium ascorbate) \\
\hline $1500 \mathrm{IU}$ Vitamin D3 \\
\hline $100 \mathrm{mg}$ Vitamin E (as mixed tocopherols, including gamma tocopherol) \\
\hline $50 \mathrm{mcg}$ K1, $50 \mathrm{mcg}$ K2 \\
\hline $30 \mathrm{mg}$ Vitamin B1 (as thiamin hydrochloride) \\
\hline $40 \mathrm{mg}$ Vitamin B2 (Riboflavin) \\
\hline $50 \mathrm{mg}$ Vitamin B3 (as inositol hexanicotinate) \\
\hline $20 \mathrm{mg}$ Pyridoxine hydrochloride, 20 mg pyridoxal 5 phosphate (P5P) \\
\hline $600 \mathrm{mcg}$ MTHF (methyl-tetra-hydrofolate) \\
\hline $600 \mathrm{mcg}$ for Vitamin B12 as methylcobalamin \\
\hline $500 \mathrm{mcg}$ Biotin \\
\hline $30 \mathrm{mg}$ Pantothenic acid (as calcium d-pantothenate) \\
\hline $100 \mathrm{mcg}$ lodine (as potassium iodide) \\
\hline $350 \mathrm{mcg}$ Lithium (as lithium orotate) \\
\hline $250 \mathrm{mg}$ Choline (as choline bitartrate) \\
\hline $100 \mathrm{mg}$ Inositol \\
\hline $100 \mathrm{mg}$ Calcium (calcium ascorbate, calcium pantothenate, calcium citrate) \\
\hline $250 \mathrm{mg}$ Magnesium (as magnesium citrate) \\
\hline $15 \mathrm{mg}$ Zinc (as zinc sulfate) \\
\hline $40 \mathrm{mcg}$ Selenium (80\% as selenomethionine, 20\% as sodium selenite) \\
\hline $1 \mathrm{mg}$ Manganese (as manganese aspartate) \\
\hline $70 \mathrm{mcg}$ Chromium (as chromium picolinate) \\
\hline $100 \mathrm{mcg}$ Molybdenum (as molybdenum nicotinate glycinate) \\
\hline $50 \mathrm{mg}$ Potassium (potassium chloride) \\
\hline $500 \mathrm{mg}$ MSM (methylsulfonylmethane) \\
\hline $50 \mathrm{mg}$ Co-Enzyme Q10 \\
\hline $45 \mathrm{mg}$ N-acetyl-cysteine \\
\hline $200 \mathrm{mg}$ Acetyl-L-carnitine \\
\hline $200 \mathrm{mg}$ L-carnitine \\
\hline
\end{tabular}

Table 2: Formulation of ANRC Essentials.
- MSM (a good source of sulfate which is low in many individuals with autism [10]

- Low-dose lithium (low in many children with autism and their mothers; the amount provided is roughly equivalent to typical daily dietary intake, and more than 100x below the levels when it is used as a psychiatric medication [10]

It is designed to improve many aspects of metabolism, including anti-oxidant support, glutathione status, mitochondrial function, and sulfate status. More information is available at www.autismnrc.org. ANRC also provides general nutritional/supplement recommendations to families.

\section{Conclusion}

Many research studies have demonstrated that children and adults with autism often have nutritional and metabolic problems, including problems with methylation, glutathione, oxidative stress, sulfation, lithium, and more. Our research has demonstrated that a vitamin/ mineral supplement can substantially improve or even normalize those nutritional and metabolic problems, and result in significant improvements in symptoms based on a large, double-blind, placebocontrolled study.

We recommend that all children and adults with autism consider a 2-3 month trial of a vitamin/mineral supplement designed for individuals with autism that is similar to the one used in our studies. By starting at a low dose, and gradually increasing it, there is minimal risk of adverse effects, and many children and adults are likely to benefit, sometimes substantially.

Financial Conflict of Interest: The author serves as President of the Autism Nutrition Research Center, www.autismNRC.org_a non-profit which produces a vitamin/mineral supplement (ANRC Essentials) for children and adults with autism. However, he works as a volunteer, and does not receive any royalties from the sales of ANRC Essentials or any nutritional supplement. He is also the director of the Autism/Asperger's Research Program at Arizona State University, http://autism.asu.edu 


\section{References}

1. Golnik AE, Ireland M (2009) Complementary alternative medicine for children with autism: a physician survey. J Autism Dev Disord 39: 996-1005.

2. Frustaci A, Neri M, Cesario A, Adams JB, Domenici E, et al. (2012) Oxidative stress biomarkers in autism: systematic review and meta-analyses. Free Radic Biol Med 52: 2128-2141.

3. James SJ, Cutler P, Melnyk S, Jernigan S, Janak L, et al. (2004) Metabolic biomarkers of increased oxidative stress and impaired methylation capacity in children with autism. Am J Clin Nutr 80: 1611-1617.

4. James SJ, Melnyk S, Jernigan S, Cleves MA, Halsted CH, et al. (2006) Metabolic endophenotype and related genotypes are associated with oxidative stress in children with autism. Am J Med Genet B Neuro psychiatr Genet. 141: 947-956

5. James SJ, Melnyk S, Fuchs G, Reid T, Jernigan S, et al. (2009) Efficacy of methylcobalamin and folinic acid treatment on glutathione redox status in children with autism. Am J Clin Nutr 89: 425-430.

6. Dolske MC, Spollen J, McKay S, Lancashire E, Tolbert L (1993) A preliminary trial of ascorbic acid as supplemental therapy for autism. Prog Neuropsycho pharmacol Biol Psychiatry17: 765-774.

7. Freedenfeld S, Hamada K, Audhya T, Adams JB (2011) Erratum Biochemical Effects of Ribose and NADH Therapy in Children with Autism. Autism Insights 3: 3-13.

8. Adams JB, George F, Audhya T (2006) Abnormally high plasma levels of vitamin $B 6$ in children with autism not taking supplements compared to controls not taking supplements. J Altern Complement Med 12: 59-63.

9. Adams JB, Holloway C (2004) Pilot study of a moderate dose multivitamin/ mineral supplement for children with autistic spectrum disorder. J Altern Complement Med 10: 1033-1039.

10. Adams JB, Audhya T, McDonough-Means S, Rubin RA, Quig D, et al. (2011a) Nutritional and Metabolic Status of Children with Autism vs. Neurotypical Children, and the Association with Autism Severity. Nutr Metab (Lond) 8: 34

11. Adams JB, Audhya T, Mcdonough-Means S, Rubin RA, Quig D, et al. (2011b) Effect of a Vitamin/Mineral Supplement on Children with Autism. BMC Pediatr 11:111. 